\title{
Molecular Screening for P53 Mutations among Tobacco Smokers in a Surveyof Awareness of Links between Tobacco, Alcohol Use and Cancer in Saudi Arabia
}

\author{
Fawaz D Alshammari*
}

\begin{abstract}
Background: Roles of tobacco and alcohol use in etiology of cancer are well established. Alterationin in P53 have essential roles neoplastic change by preventing genome mutation; the aim of this study was to assess the association between P53 mutation and tobacco and alcohol consumption, as well as to assess the epidemiology of tobacco and alcohol use as risk factors for cancer in the adult population of northern Saudi civilians. Materials and Methods: A cross-sectional survey from October 2014 to January 2015, covering 3,398 adults, was performed. P53 mutation molecular detection was performed for 100 tobacco and alcohol users, usingDNA extracted from buccal cells. Results: Of the 3,398 participants $3,253 / 3398(95.7 \%)$ responded, with a male female ratio of 1.10 : 1.00. Out of these, $24.8 \%$ had smoked tobacco in their lifetime and $2.7 \%$ were consumers of alcoholic beverages. None was identified with any P53 mutation. Conclusions: The prevalence of tobacco smoking among the northern Saudi civilians was relatively high. Females' attitudes in tobacco and alcohol related issues were found to be affected by social stigma. Tobacco and alcohol use has no link to P53 gene mutations.
\end{abstract}

Keywords: P53 gene mutation - tobacco - alcohol - cancer - Saudi Arabia

Asian Pac J Cancer Prev, 16 (16), 6845-6849

\section{Introduction}

Tobacco and alcohol consumption play an important role in mortality and morbidity in various countries (Ahmed, et al., 2003; Lopez, et al., 2006; Begg et al., 2007; Ahmed, et al., 2010). Globally, tobacco consumption is the main cause of death, resulting in millions of deaths every year, more than HIV/AIDS, tuberculosis and malaria (WHO, 2008). Cigarette and Shisha smoking are important public health concern worldwide causing many diseases including; pulmonary disease, various cancers including those of the respiratory, digestive, and genitourinary systems, some leukemias and premature death (Office of the Surgeon General, 2004; Babiker et al., 2012).

Socioeconomic factors have strong impact on tobacco use worldwide (Bobak et al., 2000; Ahmed and Mahgoob, 2007). A strong inverse relationship between socioeconomic status and smoking exists, particularly in the develop world. Such relationship indicating that the poorest and least educated populations are more likely to smoke than the other counterparts (Laaksonen et al., 2005; Wipfli and Samet, 2009).

Alcohol consumption is associated with high mortality and morbidity in both developing and developed world (Santanu et al., 2012). Alcohol abuse can cause many diseases, including; cancer of the mouth, esophagus and larynx, liver cirrhosis, and pancreatitis, social consequences, such as family and workplace-related problems, road-traffic accidents, and interpersonal violence (WHO, 2002; Ahmed et al., 2013). As a result, alcohol use has been getting more public and research attention in recent years (Ahmed, 2013).

It is evident that the prevalence of tobacco consumption is rising in the Hail region. Female participation in tobacco and alcohol related studies in the Hail - Saudi Arabia represent a major obstacle since it is considered as social stigma due to complete prohibition by law (Ginawi, 2013). Despite good knowledge about the hazards of tobacco consumption, about $25 \%$ of the medical students were found to smoke (Al-haqwi et al., 2010). Despite the strong religious belief in Saudi Arabia against the use of alcohol and other addictive substances, a great majority of the medical students in Saudi Arabia, perceived that alcohol abuse is a common problem in the community (Al-haqwi, et al., 2010). Cigarette smoking is an important public health problem in Saudi Arabia. A more intense and comprehensive tobacco control effort is needed (Jarallah, et al., 1999). Cigarette smoking is prevalent among Saudi adults in Riyadh, particularly males, most of whom begin to smoke rather early in life and continue for many years (Saeed et al., 1996).

The current study was carried out with the aims to 
assess the frequencies of tobacco smoking and alcohol consumptions among different population settings in Northern Region of Saudi Arabia (Hail Region) to provide data, which help in future planning to eliminate these habits, particularly among young generations.

\section{Materials and Methods}

This is a community-based, cross-sectional study, which was conducted in North Saudi Arabia, during the period from October 2014 to January 2015. Data was collected as a part of cancer awareness campaign that covered an area inhibited with approximately 140,000 individuals. People were gathered in certain public entities (University colleges, Health centers, Community gatherings), then were requested to fill a questionnaire about tobacco and alcohol habits and other information regarding their attitudes towards these issues.

Buccal cells were obtained by scraping buccal mucosa for subsequence molecular analysis of P53 gene. P53 gene mutation was examined using Polymerase Chain Reaction (PCR).

Statistical analysis: Statistical analysis was performed by proportion. The SPSS software (version 16) was used for statistical analysis.

Ethical consent: A written informed consent was acquired from each respondent, ensuring strict anonymity.

\section{Results}

Out of 3398 persons, 3253 adults have responded giving a response rate of $95.7 \%$. Out of 3253 study subjects $1701 / 3253(52.3 \%)$ were males and 1552/3253 $(47.7 \%)$ were females giving a males' to females' ratio of $1.10: 1.00$.The age range of respondents was $15-77$ years with a mean of $25 \pm 8.95$ years. In this survey 808 (24.8\%), and $88(2.7 \%)$ of the respondents had smoked tobacco, and consumed alcohol, respectively in their lifetime. Out of which, 674/808 (83.4\%), and 58/88 (65.9\%) were current smokers, and alcohol abuse, respectively. On the other hand 2445 (75.2\%), and 3165 (97.3\%) never smoked tobacco, and never used alcohol, respectively

Table 1. Distribution of the Study Population by Tobacco and Alcohol Use

\begin{tabular}{lrrrr}
\hline Variable & \multicolumn{2}{c}{ Current user } & Total & Quit \\
\cline { 2 - 3 } & Yes & No & & \\
\hline Smoking & 808 & 2445 & 3253 & 134 \\
Alcohol & 88 & 3165 & 3253 & 30 \\
Live with smoker & 1001 & 2252 & 3253 & 0 \\
\hline
\end{tabular}

in their lifetime. Of the 2445 (75.2\%) never smoked tobacco, 1001 (40.9\%) were living with tobacco smokers, as shown in Table 1. In regard to the duration of smoking data were available for 421 participants. The majority of smokers have smoked tobacco for durations of $\leq 5$ years representing 211/421 (50.2\%) followed by duration of 6-15, and 16-30 constituting 158/421 (37.6\%) and 52/421 (12.4\%), respectively. The durations of alcohol use was available for 39 participants. Most users have confessed of alcohol use for durations of $\leq 5$ years representing 29/39 (74.4\%) followed by 6-10 years and $11+$ consisting $7 / 39$ $(17.9 \%)$, and $3 / 39(7.7 \%)$, in this order, as indicated in Table.2. Of the 674 smokers only $22 / 808(2.7 \%)$ have confessed that they have used tobacco in their life. On the other hand, of the 88 alcoholic users, only 2/88 (2.3\%) have confessed that they are currently using alcohol.

Data regarding tobacco use was available for 3179 participants, of whom 658 persons were tobacco users. The great majority of tobacco users were identified in the age group 19-29 years followed by 30-39, 40-49,50+ and $>18$ years representing 375/658(57\%), 155/658(2 $3.6 \%), 62 / 658(9.4 \%), 38 / 658(5.8 \%)$ and $28 / 658(4.2 \%)$ respectively, as shown in Table 2 . On the other hand, data regarding alcohol use was available for 3159 of whom 57 were alcoholic consumers. Elevated number of alcoholic was found in age range19-29 years followed by $30-39,50+, 40-49$, and $>18$ years representing $26 / 57$ (45.6\%), 13/57(22.9\%), 9/57 (15.7\%), 6/57(10.5\%)and $3 / 57(5.3 \%)$, respectively, as shown in Table 2. Notably, when calculating the percentage of tobacco users among each entire group, it was observed that tobacco use was increasing with the increase of age. Similarly the same observation was noticed among alcohol users as indicated in Figure 1.

Table 3 Summarizes, tobacco and alcohol habits among different education levels. Individuals at university levels represent the highest proportions in smoking, and alcohol

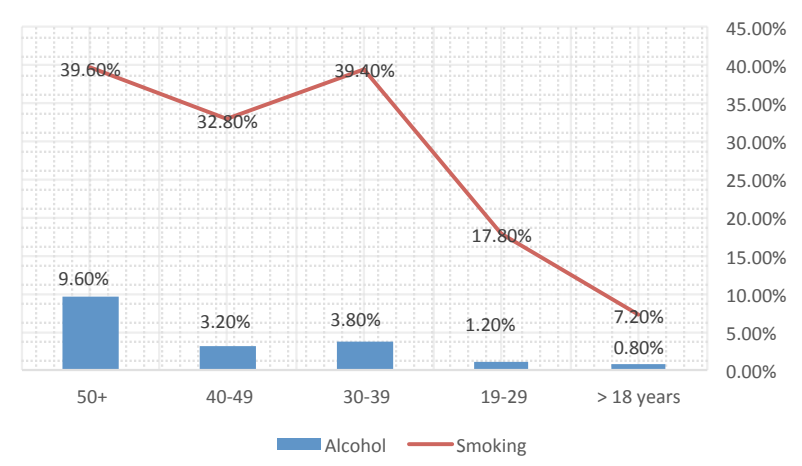

Figure 1. Description of the Study Population by age and Tobacco or Alcohol Use

Table 2. Distribution of the Study Population by age and Tobacco or Alcohol Use

\begin{tabular}{|c|c|c|c|c|c|c|c|}
\hline Category & Variable & $<18$ years & $19-29$ & $30-39$ & $40-49$ & $50+$ & Total \\
\hline \multirow[t]{2}{*}{ Smoking } & Yes & 28 & 375 & 155 & 62 & 38 & 658 \\
\hline & No & 363 & 1735 & 238 & 127 & 58 & 2521 \\
\hline Total & & 391 & 2110 & 393 & 189 & 96 & 3179 \\
\hline \multirow[t]{2}{*}{ Alcohol } & Yes & 3 & 26 & 13 & 6 & 9 & 57 \\
\hline & No & 390 & 2074 & 372 & 181 & 85 & 3102 \\
\hline Total & & 393 & 2100 & 385 & 187 & 94 & 3159 \\
\hline
\end{tabular}


Table 3. Distribution of the Study Population by Education and Tobacco and Alcohol Habits

\begin{tabular}{lccccccrr}
\hline Category & Variable & illiterate & Primary & Intermediate & High school & Graduate & Post-graduate & Total \\
\hline Smoking & Yes & 0 & 45 & 13 & 258 & 327 & 15 & 658 \\
& No & 8 & 68 & 29 & 475 & 1950 & 58 & 2588 \\
Total & & 8 & 113 & 42 & 733 & 2277 & 73 & 3246 \\
Alcohol & Yes & 0 & 7 & 1 & 19 & 27 & 3 & 57 \\
& No & 8 & 104 & 39 & 709 & 2243 & 67 & 3170 \\
Total & & 8 & 111 & 40 & 728 & 2270 & 70 & 3227 \\
\hline
\end{tabular}

Table 4. Distribution of the Study Population by Education and Tobacco and Alcohol Habits

\begin{tabular}{lccccccccrr}
\hline Category & Variable & Farmer & House wife & Labor & Student & Teacher & Employee & Medical & Other & Total \\
\hline Smoking & Yes & 1 & 1 & 2 & 235 & 37 & 214 & 31 & 102 & 623 \\
& No & 0 & 13 & 1 & 1720 & 63 & 293 & 44 & 204 & 2438 \\
Tota & & 1 & 14 & 3 & 1975 & 100 & 507 & 75 & 306 & 3061 \\
Alcohol & Yes & 0 & 0 & 0 & 14 & 6 & 13 & 3 & 8 & 44 \\
\multirow{2}{*}{ Total } & No & 1 & 14 & 3 & 2037 & 87 & 490 & 72 & 296 & 3000 \\
& & 1 & 14 & 3 & 2051 & 93 & 503 & 75 & 304 & 3044 \\
\hline
\end{tabular}

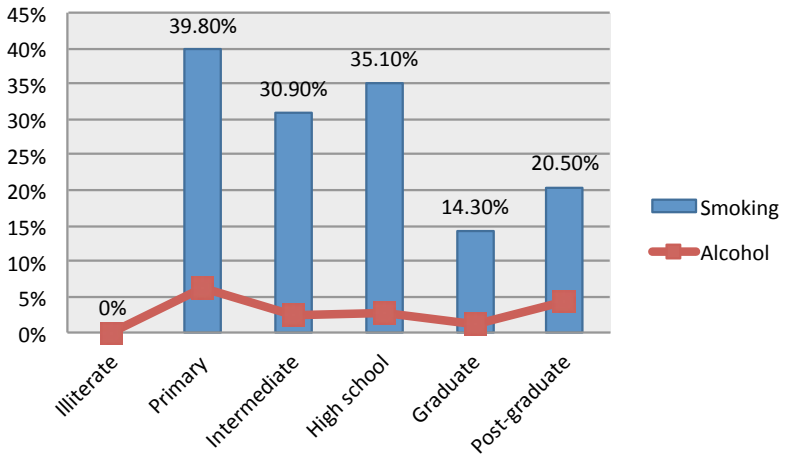

Figure 2. Description of the Study Subjects by Education and Habits within Entire Education Level

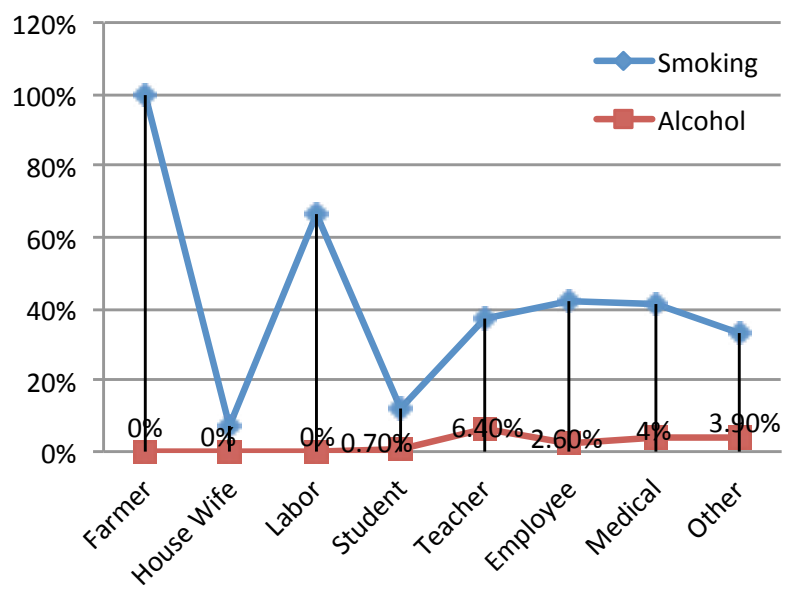

Figure 3. Description of the Study Subjects by Education and Habits within Entire Occupation Group

drink constituting, 327/658 (50\%), and 27/57 (47.3\%) respectively, followed by people at high school level representing, 258/658 (40\%), and 19/57 (33.3\%) among smokers, and alcoholic in this order. However, when calculating the percentage of smoking habits within entre education level, high percentage was observed among primary level constituting $39.8 \%$, followed by high school, intermediate, post graduate and graduate representing,
$35.1 \%, 30.9 \%, 20.5 \%$, and $14.3 \%$, respectively. Moreover, when calculating the percentage of alcohol habits within entre education level, high percentage was observed among primary representing $6.3 \%$, followed by post graduate, high school, intermediate, graduate constituting, $4.3 \%, 2.6 \%, 2.5 \%$ and $1.2 \%$, in this order, as indicated in Figure 2.

Table 4 summarizes tobacco and alcohol habits by occupation. Since, students representing the great majority of the study subjects, elevated number of smokers was found amongst students group representing 235 followed by employee, others, teachers and medical constituting 214, 102, 37, and 30 respectively. Regarding alcoholic, similarly most users were found amongst students constituting 14 followed by employees and others, representing 13 and 8 , in this order. However, when calculating the percentages within each entire occupational group, the percentages greatly differ from the proportions of numbers of users within the study population as indicated in Figure 3.

\section{Discussion}

The tobacco used in a particular product has an important effect on its chemical composition, and differs with tobacco species, growing, curing, processing and storage. Therefore, it differs in its broad health consequences including cancer. Moreover, the epidemiology of tobacco use vary from country to another and from community to another. Evaluating cancer awareness is an important step toward cancer control; as it gives the policy makers and health care providers an opportunity to recognize the influence of the interventions and do what is possible to get the anticipated outcomes. Therefore, the aim of this study was to carry out an epidemiological survey on tobacco and alcohol use in Northern Kingdom of Saudi Arabia (Hail Region), which is an area inhibited by approximately 500,000 persons.

Although, there a number of studies performed in this context, bust mostly included younger population, which is differ in this study. Of these studies, the study by 
Alshammari et al. (2013), in which Of the 475 (79.2\%), who responded to the question, whether they are currently smokers or alcohol consumers, 167/475(35.2\%) or $46 / 475(9.7 \%)$ respectively, answered yes. In the present study, $24.8 \%$, and $2.7 \%$ of the respondents had smoked tobacco, and consumed alcohol, respectively in their lifetime. The variations in these percentages might be due to the large number of participants in this study. In another study, a cross sectional approach was used where 156 students recruited to fill self-administered questionnaire which includes smoking status of student and their socio-demographic characters of parents and friends smoking status, smoking perception and alcohol use. Current tobacco smokers constitute $42.3 \%$ of the studied students with about $34.8 \%$ were cigarette smokers only, $21.2 \%$ were shisha smokers only and $40.9 \%$ were both cigarette and shisha smokers (Haytham, et al., 2014). In a recent study, 96/975(9.8\%), and 51/975(5.2\%) of the respondents medical students had smoked tobacco, and consumed alcohol, respectively in their lifetime. Of the 96 smokers, 50/96 (52\%) were males and 46/96 (48\%) were females, which giving prevalence of 50/120 (41.7\%) for males and 46/855 (5.4\%). Out of 96 smokers, 41/96 $(42.7 \%)$ were current smokers and the remaining 55/96 $(57.3 \%)$ had quit smoking. Out of the 879 never smoked individuals, $440 / 879(50.07 \%)$ were living with tobacco smokers. Of the 51 alcohol consumers, only 9/51 (17.6\%) were currently alcoholic and the remaining 42/51 (82.4\%) had quit alcohol consumption (Alshammari, et al.,2015).

The association between tobacco use and cancer was well well-known. Studies published since the 1986 IARC Monograph on "Tobacco smoking" The relationship between cigarette smoking and cancer of the lung, nasal cavities and paranasal sinuses, nasopharynx, stomach, liver, kidney etc., was strongly evidenced (Sasco, et al. 2004).

Nevertheless, this study investigated the presence of P53 mutation among tobacco users. The relationship between p53 gene mutations, tobacco smoke, and alcohol consumption was established in many cancers (Gerd, et al., 2002). Although, in this study there was no P53 mutation detected, there were many studies in this context. In a study examined p53 gene mutations in exons 5 through 8 by PCR-single-strand conformation polymorphism analysis in a cohort of 84 patients with laryngeal squamous cell carcinoma, they found p53 gene mutations were detected in $24(28.6 \%)$ cases $(95 \%$ confidence interval, $19.3 \%-39.5 \%$ ), and the GC to TA transversion (33\%) was the most common type of mutation (95\% confidence interval, $15.6 \%-55.3 \%$ ). Most mutations mapped to the p53 DNA-binding domain, which is necessary for the physiological activity of p53 as a tumor suppressor. A statistically significant association was found between p53 mutations and exposure to tobacco smoke $(\mathrm{P}=.001)$, which was the only variable significantly associated with p53 mutations in a multivariate model. The association with alcohol consumption was only at a borderline level of significance $(\mathrm{P}=0.065)$ (Ronchetti, et al., 2004).

Nevertheless, it was observed that in the present study many study subjects were living with smokers and this explore the burden of tobacco use which in most instances is considered as social stigma, particularly among females. Moreover, the stigma is at its highest levels among females which explain the small number of females' users in this study.

However, statistical figures regarding variables such as age, education and occupation have varies conditions and they were included to show the level of differences in order to stimulate further research in such context.

A limitation of the present study include the fact that data were collected via self-report. The of quantitative measures of tobacco exposure such as exhaled carbon monoxide, urine or saliva nicotine would allow a more conclusively categorized tobacco exposure in such population. Ways should be searched to come over stigma, which give rise inaccurate data.

In conclusion: Tobacco use and exposure are prevalent in Northern KSA, which require intervensions and controls. Alcohol use has low prevalence. No relationship was identified between P53 mutation and Tobacco use.

\section{Acknowledgements}

I would like to thank Prof. Dr. Hussain Gadelkarim for data analysis and revision of the manuscript and Dr. Gamal Mohmmed Alawad for helping in the collection of data.

\section{References}

Alshammari FD, Khalifa AM, Kosba AA, et al (2015). Assessment of perception of medical students in regard to links between tobacco or alcohol use and cancer. Asian Pac J Cancer Prev, 16, 2697-700.

Babiker AYY, Abas IMK, Alzohairy MA, Ahmed HG (2012). Assessment of Lung Cytological Atypia among Shisha Smokers. ISRN Pathology; Volume 2012, 676390.

Begg S, Vos T, Barker B, et al (2007). The burden of disease and injury in Australia 2003. PHE 82. Canberra: AIHW. Bobak M, Jha P, Son N, Jarvis M (2000). In: Oxford medical publications. Jha P, Chaloupka F, editor. Oxford;New York: Oxford University Press. Poverty and smoking; p. 41.

Bobak M, Jha P, Son N, Jarvis M (2000). In: Oxford medical publications. Jha P, Chaloupka F, editor. Oxford;New York: Oxford University Press. Poverty and smoking; p. 41.

Gerd P Pfeifer, Mikhail F Denissenko, Magali Olivier, Natalia Tretyakova, Stephen S Hecht and Pierre Hainaut (2002). Tobacco smoke carcinogens, DNA damage and p53 mutations in smoking-associated cancers. Oncogene ; 21(48): 7435-7451.

Ginawi IG (2013). Perception on the relationship between cancer and usage of tobacco and alcohol in hail, Saudi Arabia. $J$ Clin Diagnostic Res, 7, 2197-9.

Haytham M Hassan, Samy S Mahmoud, Mansour K Gatasha, et al (2014). Tobacco smoking among students of Al-ghad College for applied medical sciences for male in riyadh, Saudi Arabia. Int J Biol Med Res, 5, 4468-72.

Jarallah JS, al-Rubeaan KA, al-Nuaim AR (1999). Prevalence and determinants of smoking in three regions of Saudi Arabia. Tob Control, 8, 53-6.

Laaksonen M, Rahkonen O, Karvonen S, Lahelma E (2005). Socioeconomic status and smoking: analysing inequalities with multiple indicators. Eur J Public Health, 15, 262-9

Lopez AD, Mathers CD, Ezzati M, Jamison DT, Murray CJ (2006). Global and regional burden of disease and risk factors, 2001: systematic analysis of population health data. 
Lancet, 367, 1747-57.

Office of the Surgeon General (2004). National center for chronic disease prevention and health promotion (u.s.) the health consequences of smoking a report of the surgeon general. [atlanta, ga.]: u.s. public health service, national center for chronic disease prevention and health promotion. http:// www.surgeongeneral.gov/library/ smoking consequences (accessed Jun 2011).

Ronchetti D, Neglia CB, Cesana BM, et al (2004). Association between p53 gene mutations and tobacco and alcohol exposure in laryngeal squamous cell carcinoma. Arch Otolaryngol Head Neck Surg, 130, 303-6.

Saeed AA, Khoja TA, Khan SB (1996). Smoking behavior and attitudes among adult saudi nationals in riyadh City, Saudi Arabia. Tob Control, 5, 215-9.

Santanu G, Amrita S, Shuvankar M (2012). Patterns of alcohol consumption among male adults at a slum in Kolkata, India. $J$ Health Popul Nutr, 30, 73-81.

Sasco AJ, Secretan MB, Straif K (2004). Tobacco smoking and cancer: a brief review of recent epidemiological evidence. Lung Cancer, 45, 3-9.

WHO (2002). The world health report 2002-reducing risks, promoting healthy life. Geneva: World Health Organization, 250.

Wipfli H, Samet JM (2009). Global economic and health benefits of tobacco control: part1. Clin Pharmacol Ther, 86, 263-71.

World Health Organization (WHO) (2008)., Research for International Tobacco Control. WHO report on the global tobacco epidemic, 2008: the MPOWER package. Geneva: World Health Organization. http://www.who.int/tobacco/ mpower/mpower_report_full_2008. 